(2) Open Access Full Text Article

\title{
Iron oxide nanoparticles as nanocarriers to improve chlorin e6-based sonosensitivity in sonodynamic therapy
}

This article was published in the following Dove Press journal:

Drug Design, Development and Therapy

\section{Peng Zhang \\ Zhongyu Ren \\ Zhiqiang Chen \\ Jinyong Zhu \\ Jing Liang \\ Rujia Liao \\ Jian Wen}

Research Center for Nervous System Diseases, The Affiliated Hospital of Guilin Medical University, Guilin Medical University, Guilin, Guangxi, People's Republic of China
Correspondence: Jian Wen Research Center for Nervous System Diseases, The Affiliated Hospital of Guilin Medical University, Guilin Medical University, No. I5, Lequn Road, Guilin, Guangxi 54I040, People's Republic of China Tel +86 I899404 3727 Email wenjian2400@163.com
Background: Compared to the excitation light in photodynamic therapy, ultrasound in sonodynamic therapy (SDT) could easily penetrate into the deep tumor in liver. However, the photosensitizer chlorin e6 (E6) activated by ultrasound has been limited in its application in clinics for the poor water solubility of E6 and poor effect of SDT. Nanoparticles as cavitation promotors may be able to amplify the E6-mediated SDT effect and also improve its water solubility. Objective: The objective of the study was to develop an E6-based sonosensitizer with improved SDT effect and good water solubility using nanotechnology.

Materials and methods: Polyethylene glycol (PEG)ylated iron oxide nanoparticles coated with E6 (PION@E6) was prepared by means of pyrolysis and phase transfer. Characterization of PION@E6 was performed by means of transmission electron microscopy, hydrate particle size analysis, and absorption and fluorescence spectra analysis. Uptake of PION@E6 by H22 cells (a murine hepatoma cell line) was measured by inductively coupled plasma atomic emission spectroscopy. The effect of SDT on H22 cells was studied by the combination of ultrasound treatment with PION@E6 incubation. Cell viability was measured using cell counting kit-8 assay. Cell apoptosis was analyzed by flow cytometry. ROS generation was measured using DCFH-DA (2', $7^{\prime}$-dichlorodihydrofluorescein diacetate) probing kit.

Results: Absorption spectra of PION@E6 revealed successful loading of E6 onto the PIONs. It showed excellent water solubility and stability with a size of $37.86 \pm 12.90 \mathrm{~nm}$ in diameter. The fluorescence spectra of PION@E6 revealed a red-shift compared with free E6. When combined with ultrasound treatment, it showed a significantly better inhibitory effect on $\mathrm{H} 22$ cells and correspondingly higher level of intracellular ROS generation compared with free E6. Furthermore, either higher dose of PION@E6 or higher power intensity of ultrasound initiated significantly better SDT effect and correspondingly higher level of intracellular ROS generation compared with lower dose of PION@E6 or ultrasound, respectively.

Conclusion: PION@E6 is a superior potential sonosensitizer to E6 to treat tumors by SDT. Keywords: iron oxide nanoparticles, chlorin e6, sonodynamic therapy, photodynamic therapy, liver cancer

\section{Introduction}

Hepatocellular carcinoma (HCC) is the most common primary malignancy of the liver in adults. The prognosis of HCC is poor in most patients, because the majority of cases are often diagnosed at a late stage and the current treatment options are rather limited for their cytotoxicity and poor efficacy. As we know, conventional cancer treatment modalities, such as chemotherapy and irradiation, have several limitations including poor patient compliance, adverse drug reactions, and impairment of the host immune system. ${ }^{1}$ 
Recently, photodynamic therapy (PDT), a ROS-mediated cancer treatment, has emerged as a potential alternative for its minimal invasiveness, in which the photosensitizers are used to generate ROS under light activation, thus causing cell apoptosis and necrosis. ${ }^{2}$

However, clinical applications of PDT have been hindered by the fact that photosensitizers produce ROS in the presence of light, which cannot reach the deep tissues in the body. ${ }^{3}$ Although considerable efforts to improve the penetration depth of light using a near-infrared (NIR) laser have been made, skin absorption of NIR light and radiative losses still pose a major challenge. ${ }^{4}$ To overcome these issues, it is necessary to develop a new system to generate ROS in deep tissues.

Non-radiative ultrasound can penetrate much deeper into biological tissue owning to its low tissue attenuation coefficient. Additionally, ultrasound has recently emerged as a therapeutic modality in combination with photosensitizers for various cancers. ${ }^{5}$ It is thus clear that ultrasound was able to activate some photosensitizers such as chlorin e6 (E6) to induce apoptosis as well as necrosis, which has led scientists to consider sonodynamic therapy (SDT) as a possible alternative to light-based PDT. ${ }^{6,7}$ In contrast to visible light in PDT to induce ROS, SDT is a promising new noninvasive approach that utilizes low-intensity ultrasound and sonosensitizers that produce ROS by sonication. ${ }^{8}$ However, one of the major disadvantages of SDT is the high cavitation threshold, resulting in long treatment duration and high intensity of ultrasound, which can cause local hyperthermia harmful to life. ${ }^{9}$

To address the local hyperthermia, some researchers have found an appropriate approach to decrease intensity threshold of cavitation. Tuziuti et $\mathrm{al}^{10}$ have demonstrated that the existence of particles in a liquid provides a nucleation site for cavitation bubble due to its surface roughness. Indeed, this fact leads to a decrease in the cavitation threshold that is responsible for the increase in collapsing of cavitation during ultrasound treatment. Therefore, nanocarriers such as silica and iron oxide nanoparticles (IONs) could be considered as cavitation promoters to improve the E6-based sonosensitivity. ${ }^{11}$ IONs are promising nanocarriers for E6 loading because they are the only magnetic nanoparticles (MNPs) approved for clinical use by the United States Food and Drug Administration ${ }^{12}$ and the method for preparation is relatively simple. Moreover, MNPs could be used in magnetic resonance imaging, which could trace when MNPs accumulate at the highest peak in vivo and thus tell the exact time point for ultrasound treatment. ${ }^{13}$

Thus, in this work, we developed a E6-based sonosensitizer by using polyethylene glycol (PEG) functionalized IONs to load E6, in which PEG is commonly used to functionalize the surface of nanoparticles to improve their in vivo stability and to avoid uptake by the reticular endothelial system.

\section{Materials and methods Preparation of PION@E6}

Chemicals including acetone, ethanol, ferrous chloride $\left(\mathrm{FeCl}_{2}\right)$, tris(acetylacetonato)iron(III) $\left(\mathrm{Fe}(\mathrm{acac})_{3}\right)$, oleic, oleic acid, oil amine, 1,2-distearoyl-sn-glycero-3-phosphoethanolamineN-[amino (PEG)-2000] (DSPE-PEG 2000), and E6 were purchased from Guoyao Chemical Co. (Shanghai, China). H22 cells (a murine hepatoma cell line) were purchased from the Shanghai Cell Research Center of the Chinese Academy of Sciences (Shanghai, China). RPMI 1640 medium and FBS were bought from Thermo Fisher Scientific (Waltham, MA, USA).

IONs coated with oleic acid were prepared by means of high temperature pyrolysis. Briefly, $1 \mathrm{mmol}$ of $\mathrm{FeCl}_{2}$ solution, $6 \mathrm{mmol}$ of oleic acid, and $6 \mathrm{mmol}$ of oil amine were added into $20 \mathrm{~mL}$ of oleic by flushing the reaction medium with a nitrogen gas, and then heated to $100^{\circ} \mathrm{C}-120^{\circ} \mathrm{C}$ for 1 hour. Thereafter, $2 \mathrm{mmol}$ of $\mathrm{Fe}(\mathrm{acac})_{3}$ was added into the above mixture and heated to $180^{\circ} \mathrm{C}-220^{\circ} \mathrm{C}$ for 30 minutes, and then continued to $280^{\circ} \mathrm{C}-300^{\circ} \mathrm{C}$ for another 30 minutes to generate oleic acidcoated IONs. After the mixture containing oleic acid-coated IONs cooled to room temperature, $75 \mathrm{~mL}$ of anhydrous ethanol was added into the mixture to collect oleic acid-coated IONs by magnetic separation. Herein, the oleic acid-coated IONs will be named MNPs in the following context for it could be magnetically separated. Thereafter, the MNPs were further washed by adding $35 \mathrm{~mL}$ of acetone and centrifugated, and the final collected MNP sediment was dissolved in $35 \mathrm{~mL}$ of chloroform for the following preparation protocol.

To prepare PION@E6 with the characteristics of small size and good water solubility, $50 \mathrm{mg}$ of DSPE-PEG 2000 and $10 \mathrm{mg}$ of E6 were dissolved in $5 \mathrm{~mL}$ of trichloromethane, and $10 \mathrm{~mL}$ of the above collected MNP was added to the mixture. After ultrasonic dispersion, $5 \mathrm{~mL}$ of deionized water was added to the mixture, and it was then rotary evaporated to clear away the trichloromethane. After ultrasonic dispersion and cooling to room temperature, the supernatant aqueous phase solution containing MNP@E6 (or PION@E6) was collected and the aggregates were removed by microfiltration and ultrafiltration.

\section{Characterization of the prepared nanomaterials}

The hydrate particle size was measured using a Brookhaven ZetaPlus Particle Analysis Device (Brookhaven Instruments 
Corporation, Holtsville, NY, USA). The zeta potential was measured using Zeta Potential Device (Nanjing Fuxin Analysis, Nanjing, China). The morphology and structure of PION@E6 were characterized by Philips CM300 transmission electron microscopy (TEM). UV-Vis/NIR spectra analysis of free E6 and PION@E6 were carried out using a UV-2700 UV-VIS spectrophotometer (Shimadzu Corporation, Kyoto Prefecture, Japan). Fluorescent spectra of free E6 and PION@E6 was analyzed by F-7000 Fluorescence Spectrophotometer (Hitachi, Tokyo, Japan). Absorption and fluorescence measurements were performed in $1 \times 1 \mathrm{~cm}$ quartz cell at room temperature, and deionized water was used as a solvent. For spectral measurement, the obtained solution of PION@ E6 was dissolved 100 times in deionized water. Meanwhile, stock solution of E6 at the concentration of $1 \mathrm{mg} / \mathrm{mL}$ was prepared in $20 \%$ ethanol and further diluted in deionized water 100 times, and the final concentration of E6 was $10 \mu \mathrm{g} / \mathrm{mL}$.

\section{Cell culture}

To avoid the cell injury incurred by detaching from plate's wall in the following ultrasound treatment, the murine hepatocarcinoma $\mathrm{H} 22$ cells were selected and cultured floating in RPMI 1640 medium containing 10\% FBS, $100 \mathrm{U} / \mathrm{mL}$ penicillin $\mathrm{G}$, and $100 \mu \mathrm{g} / \mathrm{mL}$ streptomycin in a $37^{\circ} \mathrm{C}$ incubator containing $5 \% \mathrm{CO}_{2}$. Medium was replaced every 24 hours.

\section{Determination of cell viability using a cell counting kit-8 (CCK-8) assay}

CCK-8 (Dojindo, Kumamoto, Japan) was used to measure cell viability according to the manufacture's instruction. In brief, $\mathrm{H} 22$ cells $\left(1.0 \times 10^{4}\right.$ cells/well $)$ were seeded in 96-well plates for 72 hours, and then CCK-8 reagent $(10 \mu \mathrm{L})$ was added to each well. Subsequently, the plate was incubated at $37^{\circ} \mathrm{C}$ for 8 hours. The OD 450 values, as a measurement of cell viability, were determined using BioTek microplate reader (BioTek, Winooski, VT, USA) and the relative cell viability $(\%)$ was calculated by test/control $\times 100 \%$. Notably, the OD450 value of each well either for test or for control should be counted by subtracting the background OD450 value, which was measured immediately after the addition of CCK-8 reagent.

\section{ROS assay}

ROS-sensitive fluorescence indicator, DCFH-DA $\left(2^{\prime}, 7^{\prime}\right.$ dichlorodihydrofluorescein diacetate) (Sigma-Aldrich Co., St Louis, MO, USA), was used to determine the intracellular ROS generation. Briefly, H22 cells were seeded at $1.0 \times 10^{4}$ cells/well in 96-well plates for 24 hours, and then the cells were treated by SDT for 30 minutes to induce ROS generation. After the cells were incubated with DCFH-DA at a final concentration of $20 \mu \mathrm{M}$ for 30 minutes, the fluorescence intensity was measured at an excitation wavelength of $485 \mathrm{~nm}$ and an emission wavelength of $530 \mathrm{~nm}$ using a SpectraMax fluorescence microplate reader (Molecular Devices LCC, Sunnyvale, CA, USA). The relative intensity of dichlorodihydrofluorescein was determined at a wavelength of $535 \mathrm{~nm}$ as compared with sham group cells. Noticeably, the background dichlorodihydrofluorescein of each well should be subtracted during ROS assay.

\section{Analysis of cell apoptosis by flow cytometry (FCM)}

The following protocol was processed using BD Pharmingen Apoptosis Detection Kit (BD Biosciences, San Jose, CA, USA), and the FCM analysis was performed using Attune NxT Acoustic Focusing Cytometer (Thermo Fisher Scientific). Briefly, the collected cells were washed twice with cold PBS and resuspended in $1 \times$ binding buffer at a concentration of $1 \times 10^{4}$ cells $/ \mathrm{mL}$. Thereafter, $100 \mu \mathrm{L}$ of the solution was transferred to a $5-\mathrm{mL}$ culture tube, in which $5 \mu \mathrm{L}$ of FITC Annexin $\mathrm{V}$ and $5 \mu \mathrm{L}$ of propidium iodide (PI) were added. After gentle vortex mixing, the cells were incubated for 15 minutes at room temperature in the dark, and then $400 \mu \mathrm{L}$ of $1 \times$ binding buffer was added to each tube for FCM analysis.

\section{Effect of SDT on $\mathrm{H} 22$ cells}

As illustrated in Figure 1, H22 cells were seeded in 96-well plates. During the plating, a continuous ultrasonic wave with a frequency of $500 \mathrm{KHz}$ was generated by Xinda Ultrasound Generator (Guilin Xinda Inc., Guilin, China). An adaptor

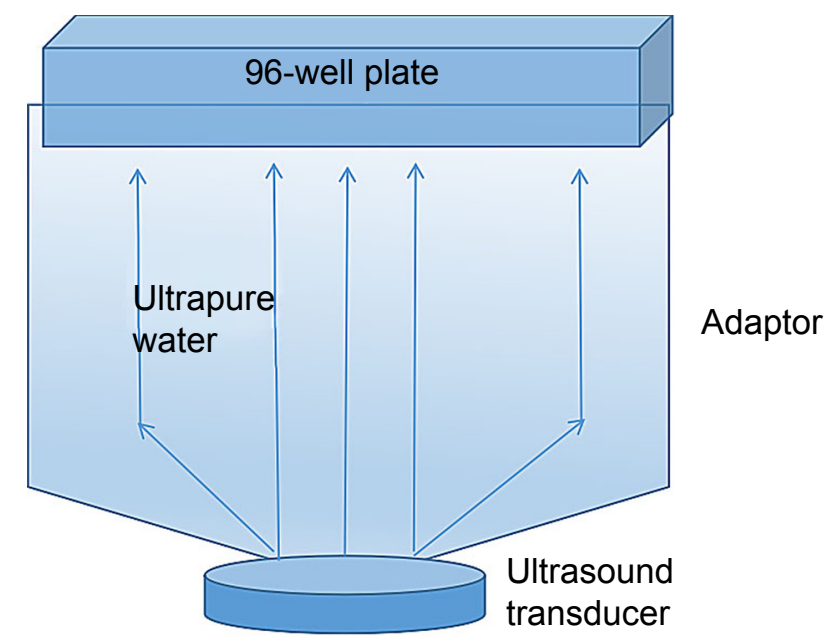

Figure I Schematic illustration of ultrasound treatment in SDT. Abbreviation: SDT, sonodynamic therapy. 
filled with ultrapure water was built to connect the 96-well plates containing the cells with ultrasound plane transducer ( $3 \mathrm{~cm}$ in diameter). When filled with ultrapure water, the adaptor creates highly reproducible measurement conditions at a fixed perpendicular distance $(4.8 \mathrm{~cm})$ from the transducer to 96 -well plates. Even with exposure to ultrasound intensity of $0.8 \mathrm{~W} / \mathrm{cm}^{2}$ for 20 minutes, maximum temperature recorded of the ultrapure water was $37^{\circ} \mathrm{C}$ in the adaptor container during ultrasound treatment.

For in vitro SDT experiments, $\mathrm{H} 22$ cells $\left(1.0 \times 10^{4}\right.$ cells/well $)$ seeded in 96-well plates were added with either PION@E6 or free E6 at various concentrations. After incubation for 12 hours, the experimental groups were exposed to ultrasound for 20 minutes while no exposure was given to the control group. Afterward, all samples were incubated in dark for another 8 hours. Thereafter, the CCK- 8 assay was carried out to determine the relative cell viability.

To test whether the SDT effect of PION@E6 is significantly superior to free E6, H22 cells were incubated with either $50 \mu \mathrm{g} / \mathrm{mL}$ of PION@E6 or $50 \mu \mathrm{g} / \mathrm{mL}$ of E6 for 12 hours and followed with $0.4 \mathrm{~W} / \mathrm{cm}^{2}$ of ultrasound for 20 minutes. Then, the cell viability was examined 8 hours after the ultrasound treatment using a CCK-8 assay.

To test whether the dose change of PION@E6 exerts an influence on the SDT effect on $\mathrm{H} 22$ cells, the H22 cells were incubated with different concentrations of PION@E6 $(0,50$, and $100 \mu \mathrm{g} / \mathrm{mL})$ for 12 hours and followed with $0.4 \mathrm{~W} / \mathrm{cm}^{2}$ of ultrasound treatment for 20 minutes. Then, the cell viability was examined 8 hours after the ultrasound treatment using a CCK-8 assay.

To test whether the change of ultrasound power exerts an influence on the SDT effect on $\mathrm{H} 22$ cells, the $\mathrm{H} 22$ cells were treated with $50 \mu \mathrm{g} / \mathrm{mL}$ of PION@E6 for 12 hours and followed with different power intensities of ultrasound treatment $\left(0,0.4\right.$, and $\left.0.8 \mathrm{~W} / \mathrm{cm}^{2}\right)$ for 20 minutes. Then, the cell viability was examined 8 hours after the ultrasound treatment using a CCK-8 assay.

\section{Cellular uptake of PION@E6 nanoparticles by inductively coupled plasma atomic emission spectroscopy (ICP-AES)}

To quantitatively determine the cellular uptake of PION@ E6 using ICP-AES, murine hepatocarcinoma H22 cells were cultured in RPMI-1640 medium with 10\% FBS in dishes containing different concentrations $(0,50$, and $100 \mu \mathrm{g} / \mathrm{mL})$ of PION@E6, and the collected cells were washed with PBS and centrifuged down. Thereafter, the cell pellet was dissolved in $37 \% \mathrm{HCl}$ solution at $70^{\circ} \mathrm{C}-80^{\circ} \mathrm{C}$ for 30 minutes.
Four replicates were measured, and the results were averaged with standard deviation (SD). ${ }^{14}$

\section{Statistical analysis}

Statistical analysis was performed using SPSS 13.0 software (SPSS Inc., Chicago, IL, USA). All data were expressed as mean $\pm \mathrm{SD}$ and analyzed with either one-way ANOVA or Student's $t$-test. If the $P$-value was $<0.05$, the difference was considered statistically significant.

\section{Results \\ Preparation and characterization of PION@E6}

As illustrated in Figure 2, $\mathrm{FeCl}_{2}$, oleic acid, and $\mathrm{Fe}(\mathrm{acac})_{3}$ were used to generate IONs coated with oleic acid by means of high temperature pyrolysis, and then the collected oleic acid-coated IONs, DSPE-PEG 2000, and E6 were further used for preparation of PION@E6 nanoparticles by means of phase transfer.

As revealed in Figure 3, the hydrate particle size of PION@E6 is 37.86 \pm 12.90 nm (Figure 3A), the zeta potential of PION@E6 is-23.8 mV (Figure 3B), and TEM of PION@ E6 showed uniformly well-distributed nanoparticles with an average diameter of $10 \mathrm{~nm}$ (Figure 3C). Ultraviolet and visible absorption spectrophotometry showed that E6 were incorporated onto the PION (Figure 3D). Moreover, no precipitation was observed after incubating PION@E6 in deionized water for 30 days (Figure 3E), and no significant aggregation of PION@E6 was detected after 5 weeks (Figure 3F), suggesting that PION@E6 has a good stability in water.

As shown in Figure 4, the excitation and emission behaviors of PION@E6 showed that the fluorescence excitation of PION@E6 greatly shifted to the longer wavelength in comparison to E6. This is demonstrated by the facts that two excitation peaks of $660 \mathrm{~nm}$ and $695 \mathrm{~nm}$ could be clearly seen in fluorescence spectra (Figure 4A) and further in the fluorescence imaging experiment (Figure 4B).

\section{Cell viability of $\mathrm{H} 22$ cells incubated with either PION@E6 or free E6}

After incubation with different concentrations of either PION@E6 or free E6 for 72 hours, the relative cell viability exhibited no significant difference even under high concentrations up to $100 \mu \mathrm{g} / \mathrm{mL}$, indicating that both PION@ E6 and free E6 have no obvious cytotoxicity to H22 cells (Figure 5). 


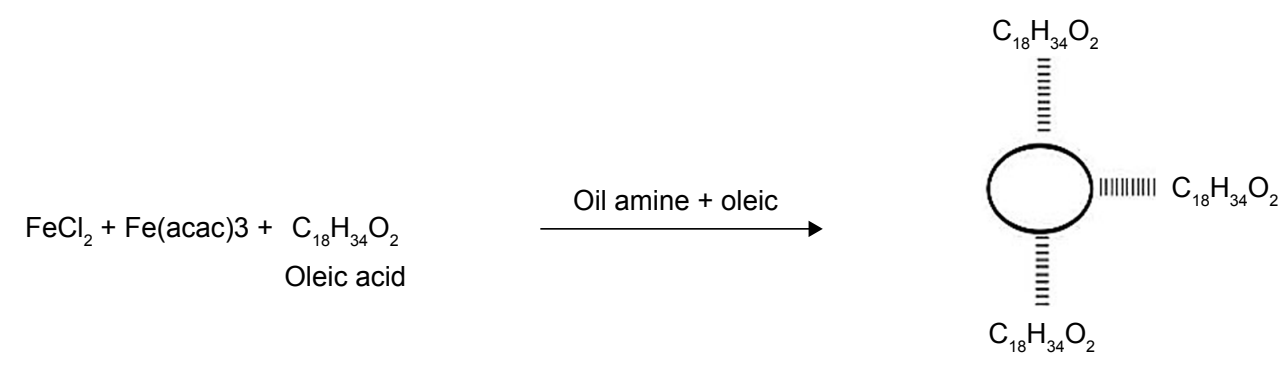

Oleic acid-coated iron oxide nanoparticles

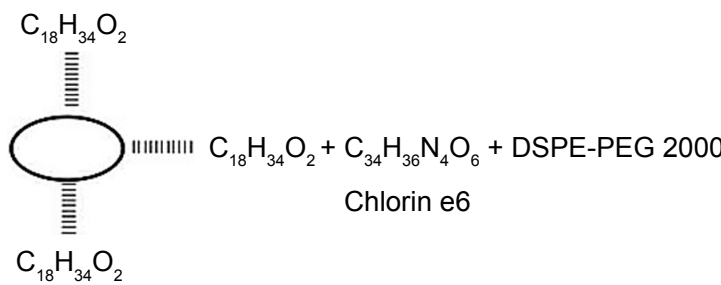

Oleic acid-coated iron oxide nanoparticles

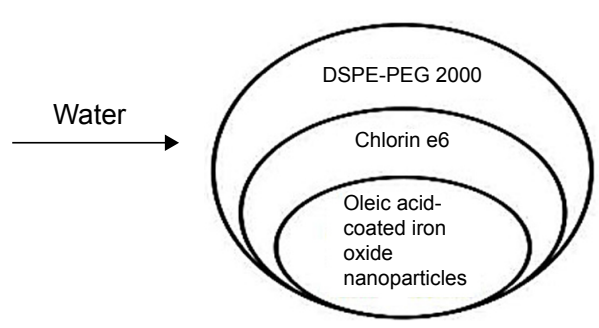

Figure 2 The schematic illustration to prepare for PION@E6.

Abbreviations: DSPE-PEG 2000, I,2-distearoyl-sn-glycero-3-phosphoethanolamine-N-[amino (PEG)-2000]; E6,chlorin e6; PEG, polyethylene glycol; PION@E6, PEGylated iron oxide nanoparticles coated with E6.

A

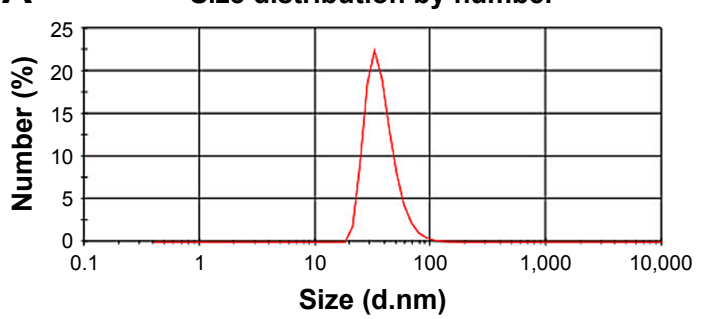

C

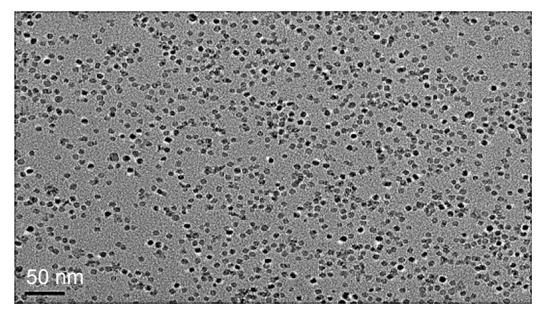

$\mathbf{E}$

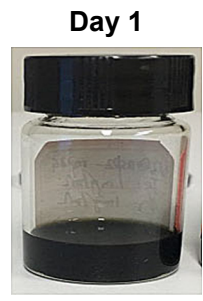

$\mathbf{F}$

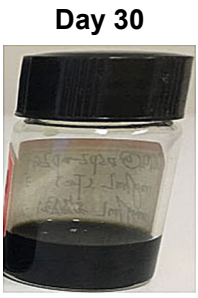

B

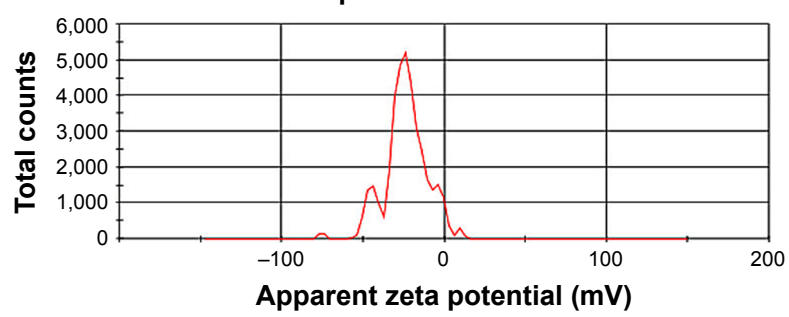

PION@E6
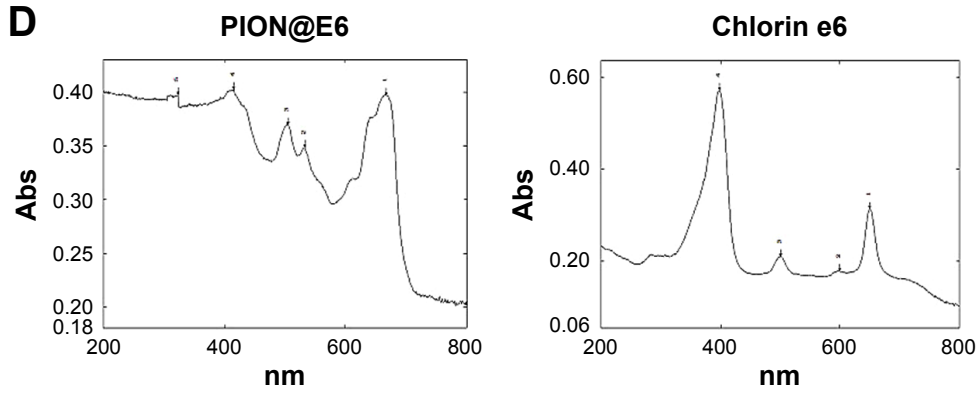

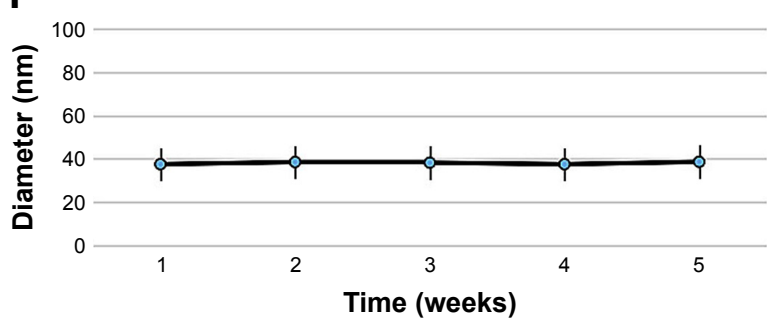

Figure 3 Characterization of PION@E6.

Notes: (A) The hydrate particle size of PION@E6. (B) The zeta potential of PION@E6. (C) TEM of PION@E6. Magnification $\times 200,000$. (D) Absorption spectra of PION@ E6 compared with that of free E6. (E) Photos of aqueous solutions of PION@E6 taken after 30 days. (F) Colloid stability test of PION@E6 in deionized water.

Abbreviations: Abs, absorbances; E6, chlorin e6; PEG, polyethylene glycol; PION@E6, PEGylated iron oxide nanoparticles coated with E6; TEM, transmission electron microscopy. 

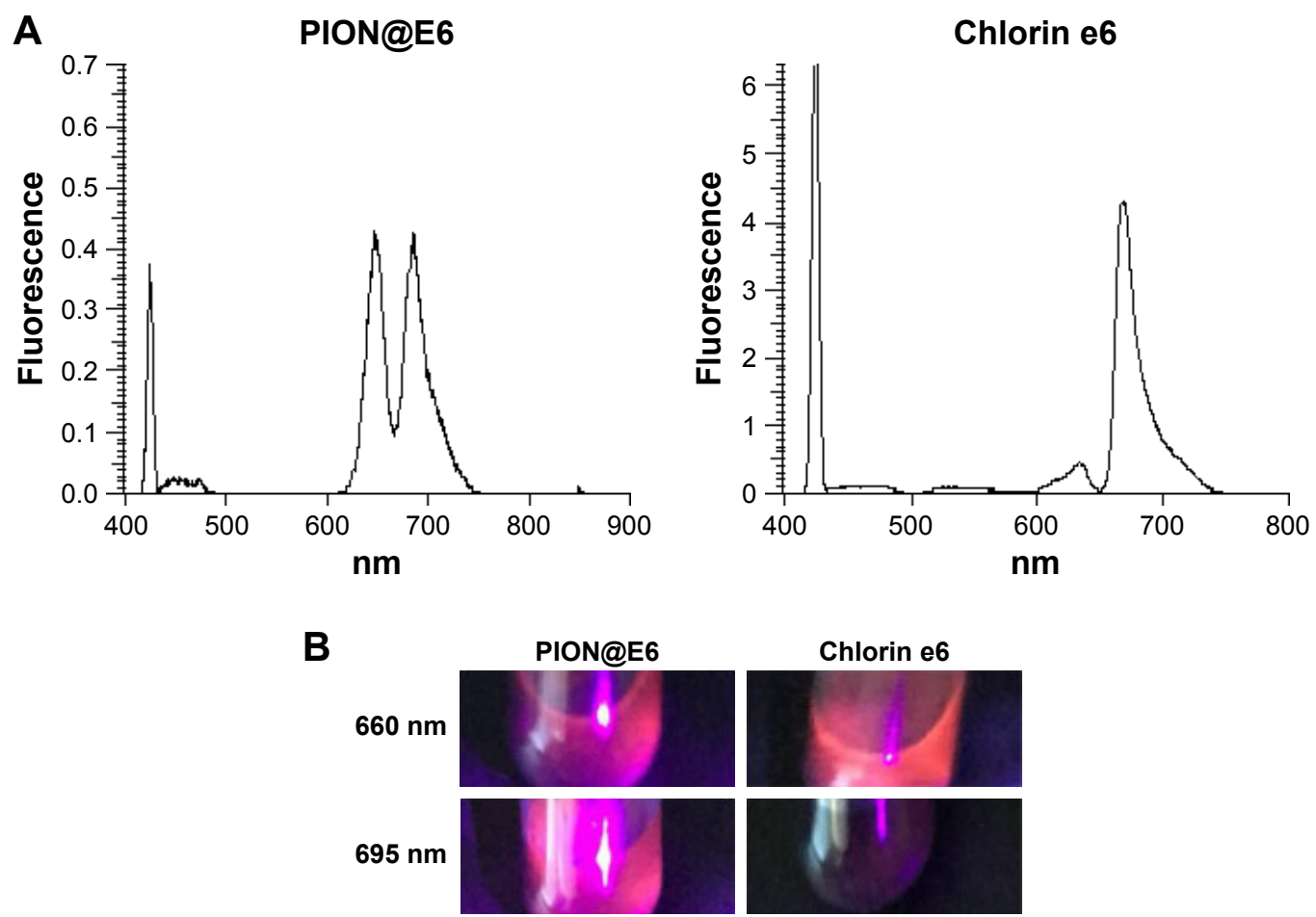

Figure 4 The fluorescence test of PION@E6 compared with that of free E6.

Notes: The concentrations of PION@E6 and free E6 were fixed at $50 \mu \mathrm{g} / \mathrm{mL}$ in this experiment. (A) Fluorescence spectra of PION@E6 and free E6. (B) Fluorescence images of PION@E6 and E6 in aqueous solutions at different excitation wavelengths (660 nm and $695 \mathrm{~nm})$.

Abbreviations: E6, chlorin e6; PEG, polyethylene glycol; PION@E6, PEGylated iron oxide nanoparticles coated with E6.

\section{Superiority of PION@E6 to E6 as sonosensitizer when combined with ultrasound}

When combined with $0.4 \mathrm{~W} / \mathrm{cm}^{2}$ intensity of ultrasound treatment, PION@E6 exhibited a significantly improved SDT effect on $\mathrm{H} 22$ cells compared with free E6 (Figure 6A); correspondingly, PION@E6 exhibited significantly higher level of ROS generation compared with free E6 (Figure 6B). Moreover, the corresponding relationships between SDT effect and ROS generation could also be found in other comparisons including

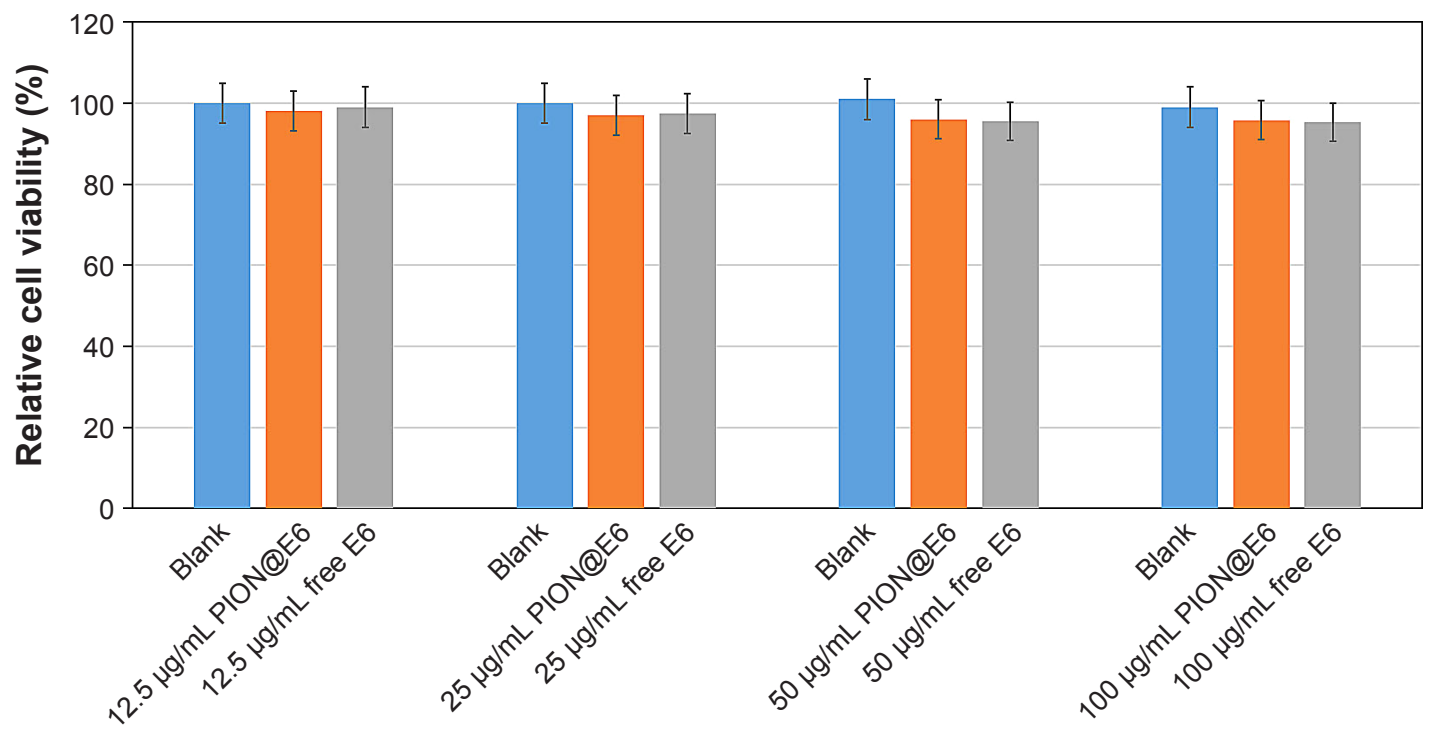

Figure 5 Cell viability of $\mathrm{H} 22$ cells incubated with either PION@E6 or free E6 at different concentrations for 72 hours. Notes: Each group consists of 8 samples. Error bars were based on SD of 8 samples.

Abbreviations: E6, chlorin e6; PEG, polyethylene glycol; PION@E6, PEGylated iron oxide nanoparticles coated with E6. 


\section{A}
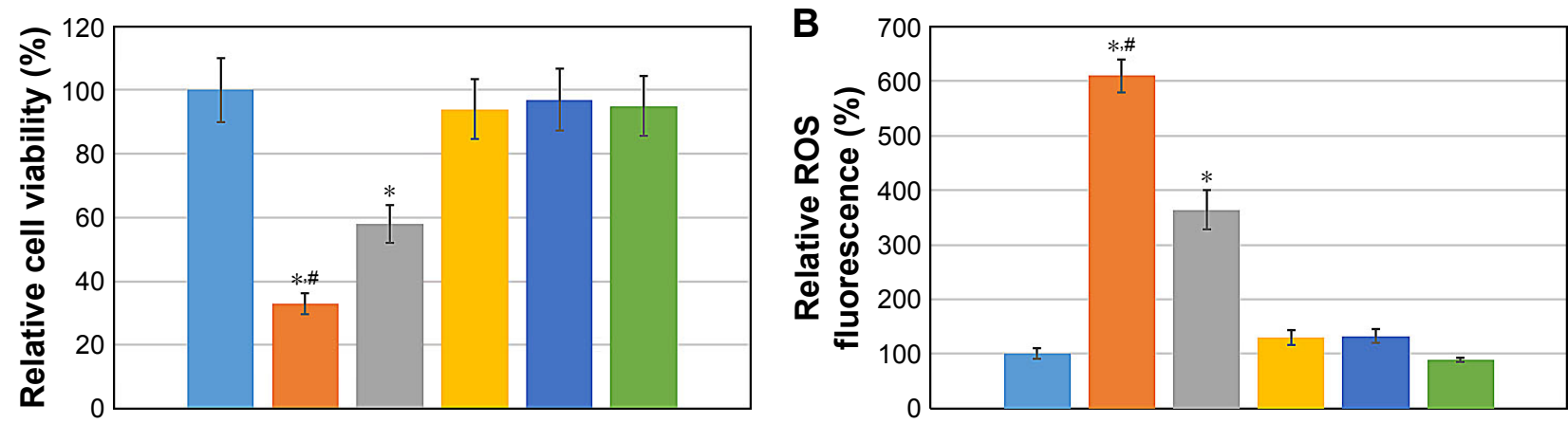

\begin{tabular}{|lll|}
\hline$\square$ Blank & $\square$ PION@E6 + ultrasound & $\square$ Free E6 + ultrasound \\
Ultrasound & $\square$ PION@E6 & $\square$ Free E6 \\
\hline
\end{tabular}

Figure 6 The effect of sonosensitizer PION@E6 on cell viability and intracellular ROS generation of H22 cells combined with an ultrasound for 20 minutes.

Notes: (A) Cell viability of $\mathrm{H} 22$ cells treated with PION@E6/free E6 (both at $50 \mu \mathrm{g} / \mathrm{mL}$ ) combined with ultrasound. (B) Intracellular ROS generation of H22 cells treated with PION@E6/free E6 (both at $50 \mu \mathrm{g} / \mathrm{mL}$ ) combined with ultrasound. Each group consists of 8 samples. Error bars were based on SD of 8 samples. *P $<0.05$, compared with the group "ultrasound". "P $<0.05$, compared with the group "E6 + ultrasound".

Abbreviations: E6, chlorin e6; PEG, polyethylene glycol; PION@E6, PEGylated iron oxide nanoparticles coated with E6.

the combination of PION@E6 with ultrasound vs ultrasound, and the combination of E6 with ultrasound vs ultrasound.

\section{Higher intensity of sound power brought higher SDT effect on $\mathrm{H} 22$ cells}

After the combination with different power intensities of ultrasound for 20 minutes, higher power intensity of ultrasound brought significantly better SDT effect on $\mathrm{H} 22$ cells (Figure 7A) and correspondingly higher level of intracellular ROS generation in $\mathrm{H} 22$ cells compared with lower power intensity of ultrasound (Figure 7B), and there were significant differences between them $(P<0.05)$.

\section{Higher dose of PION@E6 led to better SDT effect in $\mathrm{H} 22$ cells}

When combined with $0.4 \mathrm{~W} / \mathrm{cm}^{2}$ power intensities of ultrasound for 20 minutes, higher dose of PION@E6 brought significantly lower cell viability ( $36 \%$ vs $58 \%$ ) (Figure $8 \mathrm{~A}$ ), higher apoptosis rate (65.6\% vs $42.2 \%$ ) (Figure $8 \mathrm{D})$, and higher level of intracellular ROS generation $(802 \%$ vs $382 \%$ ) (Figure $8 \mathrm{~B}$ ) in $\mathrm{H} 22$ cells compared with lower dose of PION@E6 $(P<0.05)$; and there were significant differences when compared with control groups (all $P<0.05$ ). Additionally, $\mathrm{H} 22$ cells incubated with higher concentrations of PION@E6 showed significantly higher cellular iron uptake

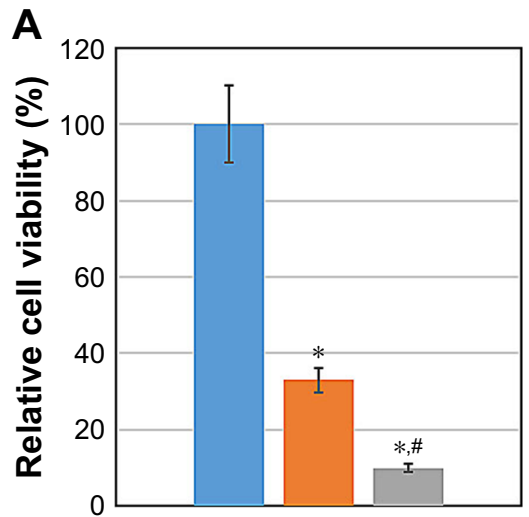

B

$$
0 \mathrm{~W} / \mathrm{cm}^{2} \text { ultrasound } \square 0.4 \mathrm{~W} / \mathrm{cm}^{2} \text { ultrasound } \square 0.8 \mathrm{~W} / \mathrm{cm}^{2} \text { ultrasound }
$$

Figure 7 The effect of sonosensitizer PION@E6 on cell viability and intracellular ROS generation of H22 cells combined with different power intensities of ultrasound for 20 minutes.

Notes: (A) Cell viability of $\mathrm{H} 22$ cells treated with different power intensities of ultrasound after incubation with $50 \mu \mathrm{g} / \mathrm{mL}$ PION@E6 for I2 hours. (B) Intracellular ROS generation of $\mathrm{H} 22$ cells treated with different power intensities of ultrasound after incubation with $50 \mu \mathrm{g} / \mathrm{mL}$ PION@E6 for 12 hours. Each group consists of 8 samples. Error bars were based on SD of 8 samples. $* P<0.05$, compared with the group " $0 \mathrm{~W} / \mathrm{cm}^{2}$ ultrasound". " $P<0.05$, compared with the group " $0.4 \mathrm{~W} / \mathrm{cm}^{2}$ ultrasound". Abbreviations: E6, chlorin e6; PEG, polyethylene glycol; PION@E6, PEGylated iron oxide nanoparticles coated with E6. 
A

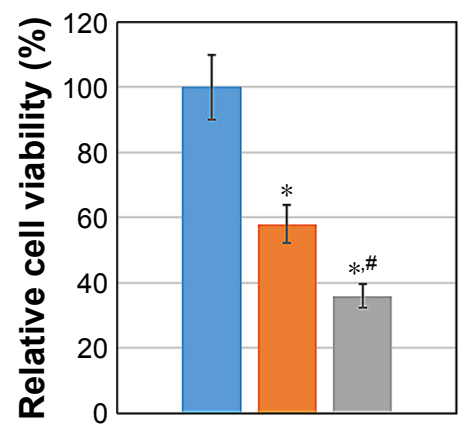

B

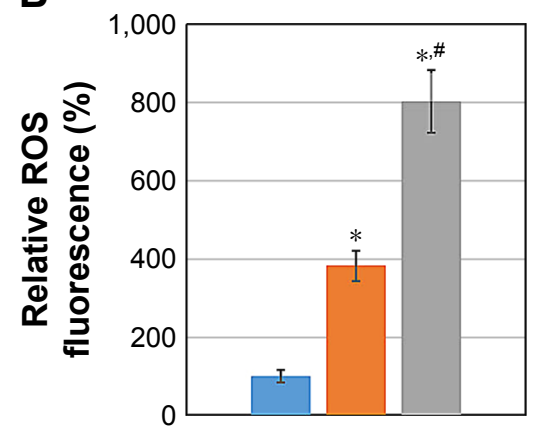

C

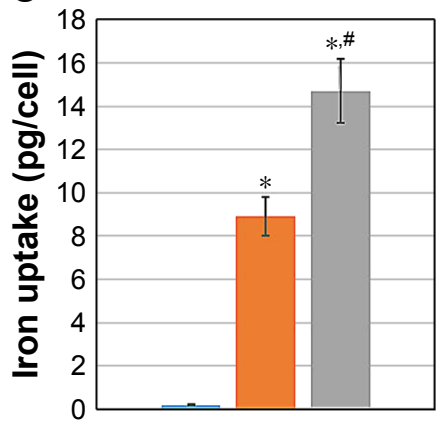

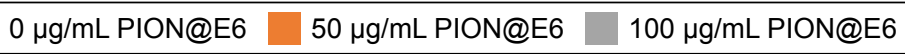

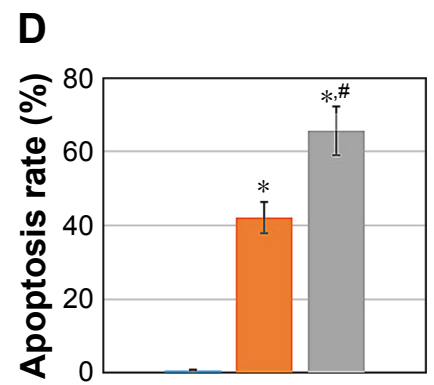

$0 \mu \mathrm{g} / \mathrm{mL}$ PION@E6

$50 \mu \mathrm{g} / \mathrm{mL}$ PION@E6

$100 \mu \mathrm{g} / \mathrm{mL}$ PION@E6

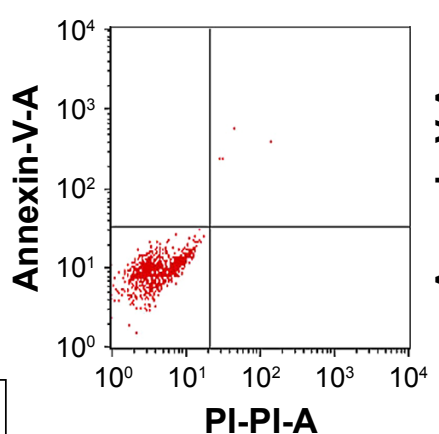

$0 \mu \mathrm{g} / \mathrm{mL}$ PION@E6
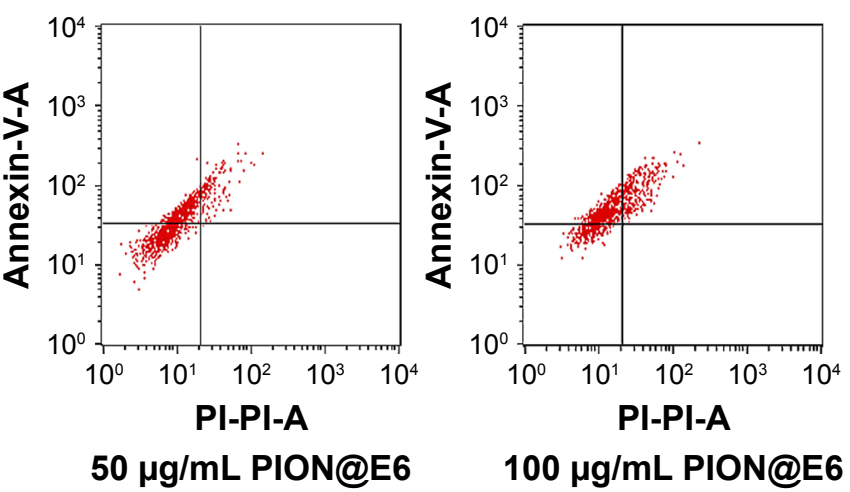

Figure 8 The effect of different concentrations of PION@E6 on cellular iron uptake of $\mathrm{H} 22$ cells and their effect on cell viability, intracellular ROS generation as well as apoptosis combined with $0.4 \mathrm{~W} / \mathrm{cm}^{2}$ power intensities of ultrasound for 20 minutes.

Notes: (A) Cell viability of H22 cells treated with different concentrations of PION@E6 combined with ultrasound. (B) Intracellular ROS generation of H22 cells treated with different concentrations of PION@E6 combined with ultrasound. (C) Cellular iron uptake of H22 cells incubated with different concentrations of PION@E6. (D) Apoptosis rate of $\mathrm{H} 22$ cells treated with different concentrations of PION@E6 combined with ultrasound. For (A and B), each group consists of 8 samples. For (C and D), each group consists of 4 samples. Error bars were based on SD of all samples in each group. *P<0.05, compared with the group "0 $\mu g / \mathrm{mL} P I O N @ E 6$ ". $P<0.05$, compared with the group " $50 \mu \mathrm{g} / \mathrm{mL}$ PION@E6".

Abbreviations: E6, chlorin e6; PEG, polyethylene glycol; PION@E6, PEGylated iron oxide nanoparticles coated with E6.

compared with that with lower concentrations of PION@E6 $(P<0.05)$ (Figure 8C).

\section{Discussion}

Usually, PEG was adopted to maintain circulation stability in the blood. Absorption spectra and size distribution of PION@ E6 directly demonstrated the successful PEG functionalization in PION@E6. As expected, our PEGylated PION@E6 possess brilliant solubility and stability. It can be seen that PEGylation of PION@E6 could keep PION@E6 particles well dispersed and dissolved in the aqueous solution without obvious precipitation for a long time (Figure 3E), suggesting that PION@E6 has a good stability, which was further demonstrated by the result of colloid stability test that no significant aggregation of PION@E6 nanoparticles was detected even after 5 weeks (Figure 3F). Also it could be inferred that the loading of E6 would not affect the dispersity and stability of PION@E6. ${ }^{15}$
PEG functionalization offers the PION@E6 with excellent water solubility that, together with the small size of $37 \mathrm{~nm}$ in diameter, is assumed to enable the PION@E6 particles to escape from the phagocytosis of reticuloendothelial and mononuclear phagocytic systems in vivo. These facts are expected to lead to a long circulation time of PION@E6 in the blood, and a consequent tumor homing ability of PION@ E6 relying on the "enhanced permeability and retention" effect of solid tumors. ${ }^{16,17}$

After being loaded on PEGylated IONs, the excitation peak of E6 shows an obvious red-shift from $660 \mathrm{~nm}$ to 695 $\mathrm{nm}$, which locates in the NIR region with improved tissue penetration efficiency. This fact is beneficial for PION@ E6-based in vivo fluorescence imaging in the deep biological tissues. Whereas free E6 and other porphyrin-based photosensitizers during in vivo fluorescence imaging are usually excited by red light at $640-660 \mathrm{~nm}$, which could be absorbed 
by the blood owing to the existence of hemachrome in red blood cells. ${ }^{18}$ Notably, the excitation and emission behaviors of PION@E6 showed two main typical fluorescence peaks (wavelengths $660 \mathrm{~nm}$ and $695 \mathrm{~nm}$ respectively) (Figure 4), suggesting that both chemical bonding and simple physical adsorption might have happened between E6 and PIONs and contributed to the effective E6 loading on PIONs. ${ }^{19}$

Either sonosensitizers (PION@E6 or free E6) alone or exposure of low-power ultrasound alone exerted no obvious inhibitory effect on H22 cells, whereas the combination of sonosensitizers with ultrasound exposure significantly impaired the cell viability. This SDT effect mediated by PION@E6 showed a significantly higher impaired cell viability and correspondingly higher intracellular ROS level compared with that by free E6 (Figures 5 and 6). It is well established that particles provide a nucleation site for cavitation, leading to the lowering of cavitation threshold. ${ }^{19}$ PION@E6 as nanoparticles might be able to act as nucleation sites for cavitation and increase the efficiency of cavitation, whose collapsing helps E6 produce singlet oxygen. In detail, the free radical molecules generated from collapsing of cavities are in high energy states, and this energy could be transferred to the nearby E6 molecules to form the excited states of E6. The energy transferred from activated E6 to oxygen molecule produces singlet oxygen, which causes the impaired cell viability. ${ }^{19,20}$ Herein, PION@E6 as cavitation nucleus possibly decreased the cavitation threshold, which led to increased collapsing of cavitation, thus causing enhanced production of ROS that initiated cell apoptosis and impaired cell viability. ${ }^{2,10}$ These facts demonstrated that PION@E6 could dramatically enhance sonodynamic effects on cancer cell in vitro by a low-power ultrasound. Therefore, PION@ E6 is superior to E6 as a sonosensitizer.

Additionally, the enhanced SDT effects mediated by PION@E6 showed a dose-dependent manner on both PION@E6 and ultrasound (Figures 7 and 8). Higher dose of either PION@E6 or ultrasound power brought higher inhibitory effect on $\mathrm{H} 22$ cells and higher intracellular ROS generation. In each case that the inhibitory effect on H22 cells was enhanced (Figures 6-8), the level of intracellular ROS was elevated. Thus, this inhibitory SDT effect on H22 cells mediated by PION@E6 seemed to be closely related to ROS generation. It is noted that the results of cell apoptosis rates determined by FCM could be well correspond to that of impaired cell viability by CCK-8 assay (Figure $8 \mathrm{~A}$ and C). Meanwhile, H22 cells incubated with higher concentrations of PION@E6 showed higher intracellular iron uptake (Figure 8C). Collectively, these facts suggested that intracellular PION@E6 particles uptake by H22 cells may be activated by ultrasound to generate intracellular ROS, thus causing cell apoptosis and impaired cell viability on H22 cells. ${ }^{2}$ Therefore, it could be inferred that PION@ E6-mediated SDT exerts its inhibitory effect on H22 cells possibly through the ROS generation.

In fact, our preliminary research has found an excellent tumor-homing ability of PION@E6 in the H22 cells tumorbearing mice by means of in vivo fluorescence imaging after the intraperitoneal injection of 1 mg PION@E6 (the results are not shown here). However, further investigation is needed to explore the distribution of PION@E6 in the different cell types such as macrophages, tumor cells, and endothelial cells in the tumor. Furthermore, the in vivo PION@E6-mediated SDT effect on tumor-bearing mice should be elucidated. Additionally, other frequencies of ultrasound should be tested to investigate their capacity to activate the PION@E6 to generate ROS to regulate cellular functions including cell viability.

\section{Conclusion}

Results of the present investigation suggest that IONs as nanocarriers could enhance the E6-based sonosensitivity to treat tumors by SDT, and the improved inhibitory SDT effect on H22 cells mediated by PION@E6 may be related to the elevation of intracellular ROS level.

\section{Acknowledgment}

This work was supported by Guangxi Nature and Science Fund (Project No 2017GXNSFAA198112 and 2015GXNSFBA139135).

\section{Disclosure}

The authors report no conflicts of interest in this work.

\section{References}

1. Ando E, Tanaka M, Yamashita F, et al. Hepatic arterial infusion chemotherapy for advanced hepatocellular carcinoma with portal vein tumor thrombosis: analysis of 48 cases. Cancer. 2002;95(3):588-595.

2. Dolmans DE, Fukumura D, Jain RK. Photodynamic therapy for cancer. Nat Rev Cancer. 2003;3(5):380-387.

3. Wilson BC. Photodynamic therapy for cancer: principles. Can J Gastroenterol. 2002;16(6):393-396.

4. Hong G, Lee JC, Robinson JT, et al. Multifunctional in vivo vascular imaging using near-infrared II fluorescence. Nat Med. 2012;18(12): 1841-1846.

5. Rengeng L, Qianyu Z, Yuehong L, Zhongzhong P, Libo L. Sonodynamic therapy, a treatment developing from photodynamic therapy. Photodiagnosis Photodyn Ther. 2017;19:159-166.

6. Kuroki M, Hachimine K, Abe H, et al. Sonodynamic therapy of cancer using novel sonosensitizers. Anticancer Res. 2007;27(6A):3673-3677.

7. Sheleg SV, Zhavrid EA, Khodina TV, et al. Photodynamic therapy with chlorin e(6) for skin metastases of melanoma. Photodermatol Photoimmunol Photomed. 2004;20(1):21-26. 
8. Yumita N, Han QS, Kitazumi I, Umemura S. Sonodynamically-induced apoptosis, necrosis, and active oxygen generation by mono-l-aspartyl chlorin e6. Cancer Sci. 2008;99(1):166-172.

9. Sviridov AP, Osminkina LA, Nikolaev AL, Kudryavtsev AA, Vasiliev AN, Timoshenko VY. Lowering of the cavitation threshold in aqueous suspensions of porous silicon nanoparticles for sonodynamic therapy applications. Appl Phys Lett. 2015;107(12):123107.

10. Tuziuti T, Yasui K, Sivakumar M, Iida Y, Miyoshi N. Correlation between acoustic cavitation noise and yield enhancement of sonochemical reaction by particle addition. J Phys Chem A. 2005;109(21):4869-4872.

11. Chen YW, Liu TY, Chang PH, et al. A theranostic nrGO@MSNION nanocarrier developed to enhance the combination effect of sonodynamic therapy and ultrasound hyperthermia for treating tumor. Nanoscale. 2016;8(25):12648-12657.

12. Zanganeh S, Hutter G, Spitler R, et al. Iron oxide nanoparticles inhibit tumour growth by inducing pro-inflammatory macrophage polarization in tumour tissues. Nat Nanotechnol. 2016;11(11):986-994.

13. Lee N, Hyeon T. Designed synthesis of uniformly sized iron oxide nanoparticles for efficient magnetic resonance imaging contrast agents. Chem Soc Rev. 2012;41(7):2575-2589.
14. Wen J, Jiang S, Chen Z, et al. Apoptosis selectively induced in BEL7402 cells by folic acid-modified magnetic nanoparticles combined with $100 \mathrm{~Hz}$ magnetic field. Int J Nanomedicine. 2014;9:2043-2050.

15. Aslan B, Ozpolat B, Sood AK, Lopez-Berestein G. Nanotechnology in cancer therapy. J Drug Target. 2013;21(10):904-913.

16. Thambi T, You DG, Han HS, et al. Bioreducible carboxymethyl dextran nanoparticles for tumor-targeted drug delivery. Adv Healthc Mater. 2014;3(11):1829-1838.

17. Thambi T, Deepagan VG, Yoon HY, et al. Hypoxia-responsive polymeric nanoparticles for tumor-targeted drug delivery. Biomaterials. 2014;35(5):1735-1743.

18. Li Z, Wang C, Cheng L, et al. PEG-functionalized iron oxide nanoclusters loaded with chlorin e6 for targeted, NIR light induced, photodynamic therapy. Biomaterials. 2013;34(36):9160-9170.

19. Osminkina LA, Kudryavtsev AA, Zinovyev SV, et al. Silicon nanoparticles as amplifiers of the ultrasonic effect in sonodynamic therapy. Bull Exp Biol Med. 2016;161(2):296-299.

20. Pan X, Wang H, Wang S, et al. Sonodynamic therapy (SDT): a novel strategy for cancer nanotheranostics. Sci China Life Sci. 2018;61(4): 415-426.
Drug Design, Development and Therapy

\section{Publish your work in this journal}

Drug Design, Development and Therapy is an international, peerreviewed open-access journal that spans the spectrum of drug design and development through to clinical applications. Clinical outcomes, patient safety, and programs for the development and effective, safe, and sustained use of medicines are the features of the journal, which

\section{Dovepress}

has also been accepted for indexing on PubMed Central. The manuscript management system is completely online and includes a very quick and fair peer-review system, which is all easy to use. Visit http://www.dovepress.com/testimonials.php to read real quotes from published authors.

Submit your manuscript here: http://www.dovepress.com/drug-design-development-and-therapy-journal 